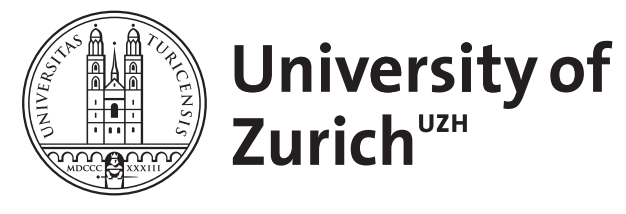

\title{
Neurotransmitters and neuromodulators
}

Steiner, Felix A

\begin{abstract}
In the central nervous system, besides the neurotransmitters, the occurrence of substances which modify neuronal excitability has been proposed. Since their effect is a matter of modulating neuronal responsiveness, these substances may be called neuromodulators. Examples of neurotransmitters or putative neurotransmitters in the central nervous system are acetylcholine, noradrenaline, dopamine, and aminoacids such as GABA, glycine, and L-glutamic acid. Under certain conditions, some of these (acetylcholine, L-glutamic acid, and GABA), as well as hormones and polypeptides (e.g., releasing factors) are considered to act as neuromodulators.
\end{abstract}

DOI: https://doi.org/10.1017/s1120962300023672

Posted at the Zurich Open Repository and Archive, University of Zurich ZORA URL: https://doi.org/10.5167/uzh-154559

Journal Article

Published Version

Originally published at:

Steiner, Felix A (1974). Neurotransmitters and neuromodulators. Acta geneticae medicae et gemellologiae, twin research, 23(Suppl S1):123-128.

DOI: https://doi.org/10.1017/s1120962300023672 


\section{GENETICS OF DISORDERS}

OF NERVES AND SYNAPSES 


\title{
NEUROTRANSMITTERS AND NEUROMODULATORS
}

\author{
FELIX A. STEINER
}

Department of Experimental Medicine, F. Hoffmann-La Roche Co. Ltd., Basel, and Institute for Brain Research, University of Zurich, Switzerland

In the central nervous system, besides the neurotransmitters, the occurrence of substances which modify neuronal excitability has been proposed. Since their effect is a matter of modulating neuronal responsiveness, these substances may be called neuromodulators.

Examples of neurotransmitters or putative neurotransmitters in the central nervous system are acetylcholine, noradrenaline, dopamine, and aminoacids such as GABA, glycine, and L-glutamic acid. Under certain conditions, some of these (acetylcholine, L-glutamic acid, and GABA), as well as hormones and polypeptides (e.g., releasing factors) are considered to act as neuromodulators.

In spite of the relative inaccessibility and great complexity of synapses in the central nervous system, important aspects of their anatomy (Pappas and Purpura 1972), biochemistry (Baldessarini and Karobath 1973, Smellie 1972), pharmacology (Phillis 1970), and physiology (Eccles 1964, McLennan 1970, Steiner 1971) have been elucidated in recent years. Among the many experimental techniques used in their study, the method of microelectrophoresis (Curtis 1964, Steiner 1971) has proved particularly efficient, because it has allowed to test the action of neurotransmitters (or of transmitter candidates) at the level of the single neurone.

Neurotransmitters are substances which are released from nerve endings following depolarization by invading action potentials, diffuse across the synaptic cleft and interact with specific receptors situated on the postsynaptic membrane. Depending on the nature of the transmitter and/or the nature of the receptor, the transmitter will either increase the $\mathrm{Na}^{+}$ conductance of the postsynaptic membrane (thereby producing excitatory postsynaptic potentials, EPSPs) or the $\mathrm{Cl}^{-}$conductance of the postsynaptic membrane (thus producing inhibitory postsynaptic potentials, IPSPs). The net sum of spatial and temporal summation of EPSPs and IPSPs determines whether or not the postsynaptic membrane gets sufficiently depolarized to generate a propagated action potential or to get hyperpolarized so as not to respond to further depolarizing stimuli. Depolarization is therefore consistent with excitation and hyperpolarization with inhibition of the postsynaptic element. The process of chemical transmission across a synapse (Table) is fast (of the order of msec), and the action of the liberated transmitter is terminated equally promptly either by enzymatic hydrolysis within the synaptic cleft (as in the case of acetylcholine) or by reuptake into the presynaptic terminal (as in the case of monoamines).

In order to qualify as a transmitter, a substance must be shown to be present in nerve terminals, to be released upon orthodromic nerve stimulation (criterion of chemical identity),

Proc. 4th Int. Congr. Neurogenet. Neuroophthalmol. (1973)

Acta Genet. Med. Gemellol. (Roma), 23: 123-128

(C) 1974 
TABLE

Biophysics AND Biochemistry of TRANSmitTER in SyNapses

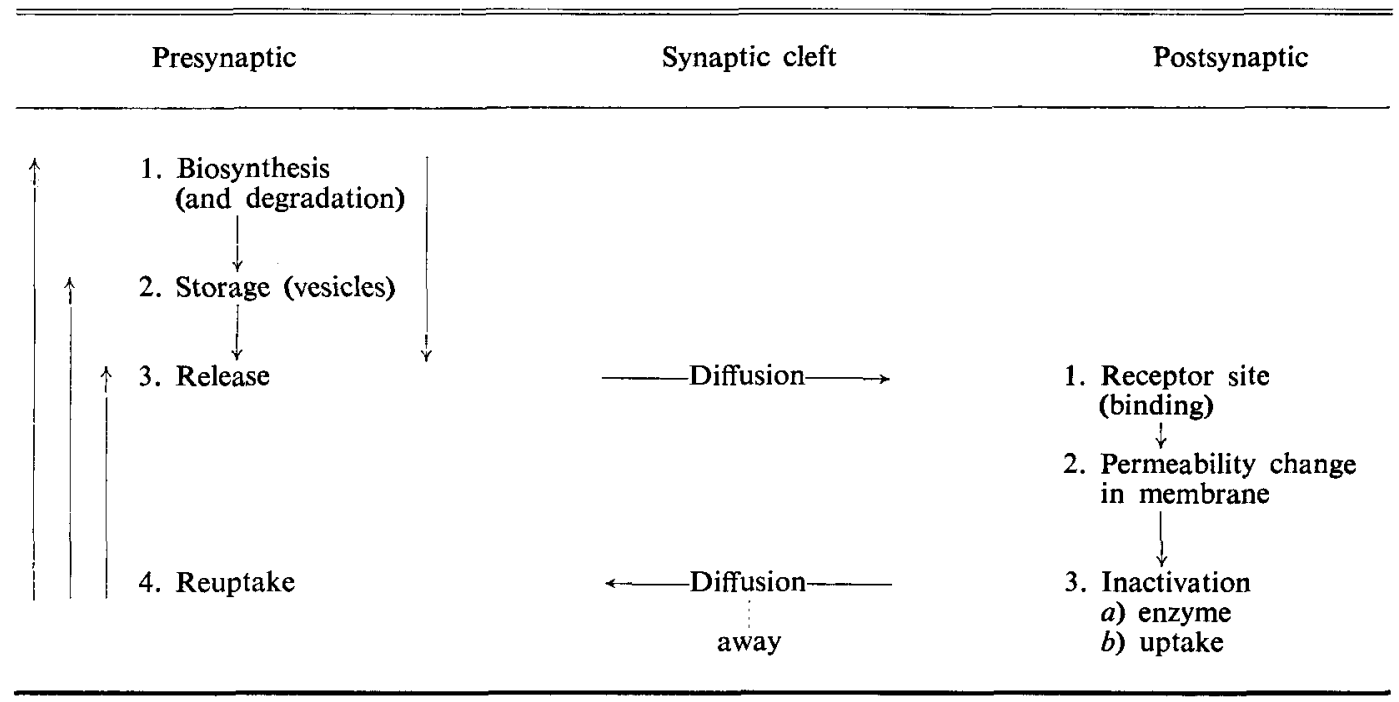

and the (enzymatic) machinery for its synthesis and its removal must be demonstrable close to the synapse. Likewise, the same substance added to the system from without must be shown to exert identical physiological effects (criterion of physiological identity) and to react in an identical way to pharmacological manipulations (criterion of pharmacological identity). For most neurotransmitters it is at present impossible to satisfy all these requirements at any given central synapse; in fact, the only instance where all these criteria have been met more or less pertains to the action of acetylcholine ( $\mathrm{ACh}$ ) on the so-called Renshaw cells of the spinal cord (Curtis 1963). In all other cases, it is customary to label likely candidates as "putative" neurotransmitters. Their list, which is growing steadily, at present includes acetylcholine, monoamines such as noradrenaline, dopamine, 5-hydroxytryptamine, histamine, and several aminoacids some of which (acidic aminoacids: glutamic acid, aspartic acid) are generally excitatory, whereas others (neutral aminoacids: GABA, glycine) have hyperpolarizing effects and therefore inhibit the postsynaptic neuronal element.

All of the above-mentioned substances have been tested by microelectrophoresis (see McLennan 1970, Phillis 1970, Steiner 1971) and the distribution of susceptible neurones and the direction of their response have been recorded in many brain areas. In this way it has been found that aminoacids such as glutamic acid or GABA elicit a rapid and stereotype response from practically all neurones (excitation in the case of glutamic acid and inhibition in the case of GABA), but that only a certain proportion of neurones respond to acetylcholine or to monoamines and that the direction of the drug effect and its time course may vary between cell populations (Steiner 1971). In addition, it has been observed that substanees which are not normally considered as putative neurotransmitters can also, in certain cases, affect the rate of discharge of single neurones if delivered by microelectrophoresis and change 
the responsiveness of neurones to neurotransmitters, either in the sense of an enhancement or of a diminuition of the response. From this latter observation the important concept of neuromodulation has been derived (Florey 1967, Steiner 1971). The list of presumed neuromodulators besides acetylcholine and aminoacids includes hormones [dexamethasone, corticosterone, triiodothyronine (T3), L-thyroxine (T4), ACTH, TRF (thryrotropin releasing factor)], prostaglandines, cAMP, substance P, and adenosine (Florey 1967, Steiner 1971 and 1973).

These substances are probably not synthesized within the presynaptic element and therefore do not meet one of the key criteria for neurotransmitters, yet they exhibit readily demonstrable effects on synaptic transmission. Some examples will be given below. Neuromodulators may act either by influencing the releasability of neurotransmitters from presynaptic terminals or the interaction of the transmitter with the postsynaptic receptor (or both), and thus may alter the net result of neurotransmitter action in a quantitative (but not in a qualitative) sense. Neuromodulators also could act directly on the postsynaptic membrane.

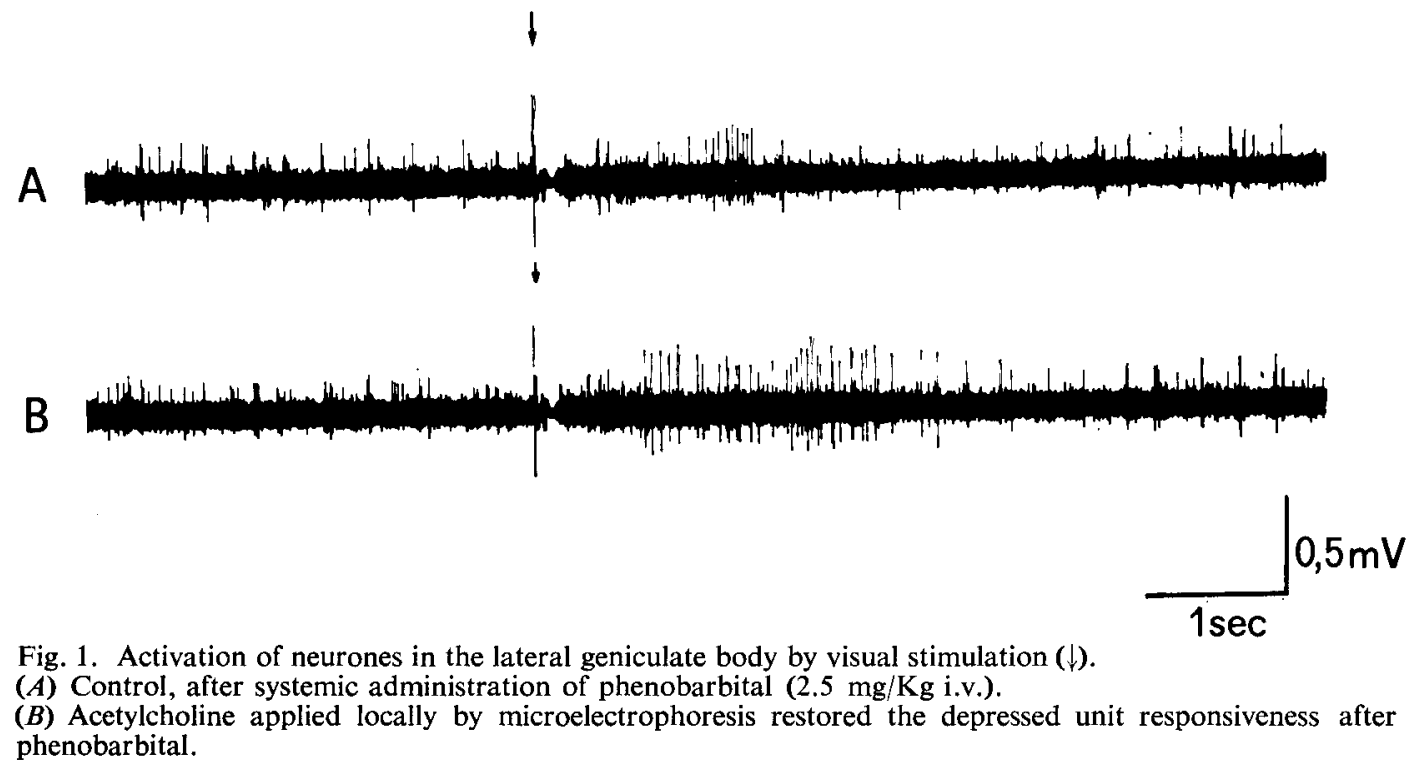

An example of a neuromodulator action is demonstrated in Fig. 1. In the lateral geniculate body of rats spontaneously active neurones responded with an activation to visual stimulation. This neuronal response was markedly depressed after systemic administration of phenobarbital. Local application by microelectrophoresis (microiontophoresis) of acetylcholine restored single unit responsiveness to visual stimulation (Steiner 1968).

A similar effect of acetylcholine was observed on a hippocampal cell (Fig. 2), which was also acetylcholine sensitive, but did not respond to visual stimulation. Extracellular acetylcholine deposition by microelectrophoresis resulted in evoked unit discharges in response to visual stimulation (Steiner 1968).

Another example: In the hypothalamus of anaesthetized rats dexamethasone and corticosterone applied locally by microelectrophoresis inhibited the spontaneous discharge rate 

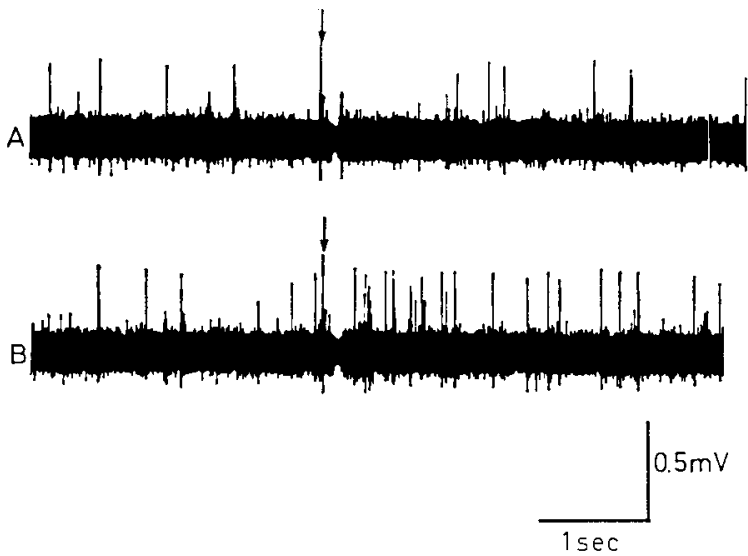

Fig. 2. Response of a hippocampal neurone to visual stimulation.

(A) Control (without effect).

(B) During acetylcholine microelectrophoresis the cell is activated by visual stimulation.

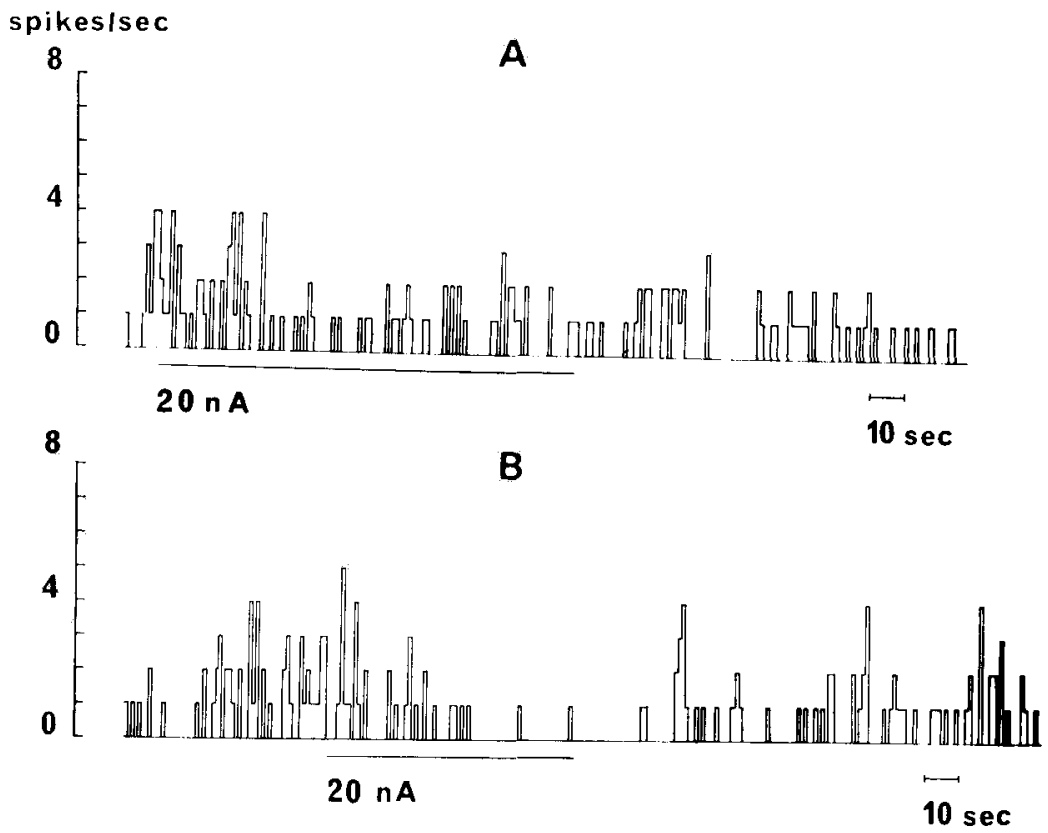

Fig. 3. Pulse rate histograms. The spontaneous discharge rate of a hypothalamic neurone (arcuate nucleus) is inhibited by microelectrophoretically applied dexamethasone-phosphate $(A)$ and corticosterone-phosphate $(B)$. Horizontal bars indicate duration of drug application. 
(Fig. 3). The steroid sensitive cells were also sensitive to ACTH applied microelectrophoretically (Fig. 4) and showed an increase of the discharge rate under the drug application (Steiner et al. 1969). These neurones could play a role in the feedback control of corticotropin releasing factor (CRF) and ACTH secretion. These hormone effects could be interpreted as a neuromodulator action (Steiner 1971).

Neuromodulators may be of far greater physiological significance than has hitherto been thought, and include classes of substances which have not been previously been suspected of exerting neuronal effects. For instance, it has recently been found that hypothalamic releasing hormones, such as TRF and LRF, not only function as peptidergic messengers to the anterior pituitary gland (Schally et al. 1973, Blackwell and Guillemin 1973) but also influence neurones within the brain. TRF, applied by microelectrophoresis, inhibited some of spontaneously active hypothalamic neurones. On the other side these TRF-sensitive neurones were activated by triiodothyronine (T3) and L-thyroxine (T4). These results are an example of a possible feedback loop in neuroendocrine control (Steiner 1973).

The diagnostic administration of TRF is commonly followed by various subjective sensations (Almqvist 1972) and it has been recommended as a therapeutic agent in certain cases of depression (Kastin et al. 1972, Prange et al. 1972, van der Vis-Melsen and Wiener 1972). LRF, on the other hand, has been shown to induce mating behaviour in rodents (Moss

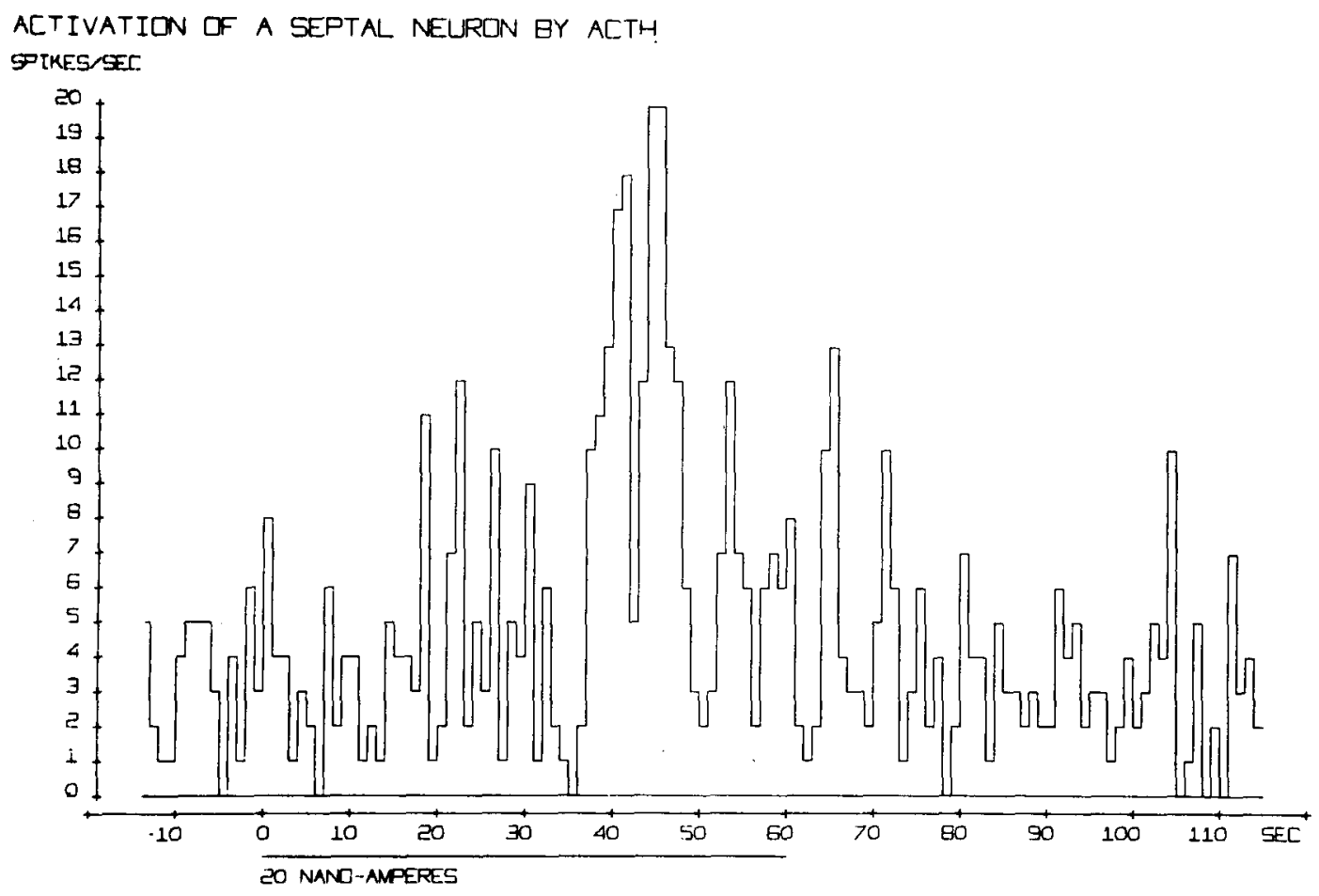

Fig. 4. Pulse rate histogram. The spontaneous discharge rate of a steroid sensitive septal neurone is activated by microelectrophoretically applied synthetic ACTH (tetracosactide). 
and McCann 1973). It is possible that these neurohormones act as true neurotransmitters by making synaptic contact with neurones in the immediate vicinity of their site of production, but it is more likely that they exhibit a more widespread effect in the sense of neuromodulators. Only further research will establish whether these substances are capable of exerting both functions or, conversely, whether bona fide transmitters may act as true neuromodulators. If this versatility of function proved to be the case, the definition of the substance as a neurotransmitter or as a neuromodulator will only hold for rigorously defined systems.

\section{REFERENCES}

Almqvist S. 1972. Clinical side effects of TRH. In R. Hall, I. Werner, H. Holgate (eds.): Thyrotropin Releasing Hormone. [Vol. 1, pp. 38-44]. Basel: Karger.

Baldessarini R.J., Karobath M. 1973. Biochemical physiology of central synapses. Ann. Rev. Physiol., 35: 273-304.

Blackwell R.E., Guillemin R. 1973. Hypothalamic control of adenohypophysial secretions. Ann. Rev. Physiol., 35: 357-390.

Curtis D.R. 1963. Acetylcholine as a central transmitter. Can. J. Biochem., 41: 2611-2618.

Curtis D.R. 1964. Microelectrophoresis. In W.L. Nastuk (ed.): Physical Techniques in Biological Research. [Vol. V, part A, pp. 144-190]. New York: Academic Press.

Eccles J.C. 1964. The Physiology of Synapses. Berlin: Springer-Verlag.

Florey E. 1967. Neurotransmitters and modulators in the animal kingdom. Fed. Proc., 26: 11641178.

Kastin A.J., Schalch D.S., Ehrensing R.H., Anderson M.S. 1972. Improvement in mental depression with decreased thyrotropin response after administration of thyrotropin-releasing hormone. Lancet, 2: 740-742.

McLennan H. 1970. Synaptic Transmission. Philadelphia: W.B. Saunders Company.

Moss R.L., McCann S.M. 1973. Induction of mating behavior in rats by luteinizing hormone releasing factor. Science, 181: 177-179.
Pappas G.D., Purpura D.P. (eds.) 1972. Structure and Function of Synapses. New York: Raven Press.

Phillis J.W. 1970. The Pharmacology of Synapses. Oxford: Pergamon Press.

Prange (jr) A.I., Lara P.P., Wilson I.C., Alltop L.B., Breese G.R. 1972. Effects of thyrotropin-releasing hormone in depression. Lancet, 2: 999-1002.

Schally A.V., Arimura A., Kastin A.J. 1973. Hypothalamic regulatory hormones. Science, 179: 341-350.

Smellie R.M.F. (ed.) 1972. Neurotransmitters and Metabolic Regulation. London: The Biochem. Society.

Steiner F.A. 1968. Influence of microelectrophoretically applied acetylcholine on the responsiveness of hippocampal and lateral geniculate neurones. Pflügers Arch., 303: 173-180.

Steiner F.A., Ruf K., Akert K. 1969. Steroid-sensitive neurones in rat brain: Anatomical localization and responses to neurohumcurs and ACTH. Brain Res., 12: 74-85.

Steiner F.A. 1971. Neurotransmitter und Neuromodulatoren. Stuttgart: Georg Thieme Verlag.

Steiner F.A. 1973. Effects of locally applied hormones and neurotransmitters on hypothalamic neurones. Proc. 4th Int. Congr. Endocrinology, Washington 1972, pp. 202-204.

Van der Vis-Melsen Mary J.E., Wiener J.D. 1972. Improvement in mental depression with decreased thyrotropin response after administration of thyrotropin-releasing hormone. Lancet, 2: 1415.

Priv. Doz. Felix A. Steiner, c/o F. Hoffmann-La Roche \& Co. Ltd, Grenzacherstrasse 124, 4002 Basel, Switzerland. 